\title{
ANTIOXIDANT, HEPATOPROTECTIVE AND ANTIMICROBIAL ACTIVITIES OF THE AERIAL PARTS OF POLYGONUM BELLARDII All.
}

\author{
Adel M. Abd El-Kader ${ }^{1}$, Alaa M. Nafady ${ }^{1}$, Amany S. Ahmed ${ }^{2}$ and Zedan Z. Ibraheim² \\ ${ }^{1}$ Department of Pharmacognosy, Faculty of Pharmacy, Al-Azhar University, Assiut 71524, Egypt \\ ${ }^{2}$ Department of Pharmacognosy, Faculty of Pharmacy, Assiut University, Assiut 71526, Egypt

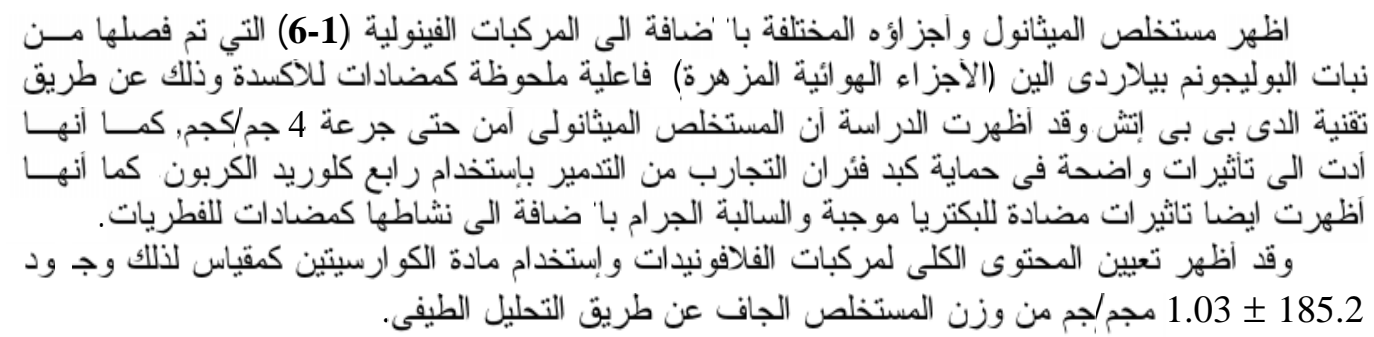

The methanolic extract of Polygonum bellardii All. (flowering aerial parts) and its fractions in addition to the isolated compounds (1-6) showed significant antioxidant potential by $\mathrm{DPPH}$ scavenging activity technique. It also showed hepatoprotective activity against carbon tetrachloride $\left(\mathrm{CCl}_{4}\right)$ induced hepatic injury in albino rats. The fractions exhibited antibacterial activity against both Gram positive and Gram negative bacteria in addition to antifungal activity. The total methanolic extract of Polygonum bellardii All. did not show signs of toxicity and mortality up to $4 \mathrm{~g} / \mathrm{kg}$ dose.

Determination of total flavonoid content with respect to quercetin spectrophotometrically indicated the presence of $185.2 \pm 1.03 \mathrm{mg} / \mathrm{g}$ dried extract.

\section{INTRODUCTION}

The genus Polygonum (Polygonaceae) comprises about 200 species mostly distributed in the North temperate countries, few are tropical or in the Southern hemisphere ${ }^{1 .}$ Many species of the genus Polygonum had been reported to exhibit a variety of interesting biological activities ${ }^{2-4}$. A variety of chemical constituents such as flavonoids ${ }^{5}$, anthraquinones $^{6}$, sesquiterpenoids ${ }^{7}$, lignans $^{8}$, coumarins $^{9}$ and stilbenes ${ }^{10}$ have been reported in the genus Polygonum.

Flavonoids are known for their powerful free radical scavenging activity ${ }^{11}$. Reactive oxygen species such as superoxide anion and hydroxyl radical, which play an important role in the toxic effects of numerous foreign compounds (xenobiotics), have been shown to be effectively detoxified by a variety of flavonoids ${ }^{12}$. In liver cells, the antioxidant activity of flavonoids has been related to an observed hepatoprotective effect of these compounds. Flavonoids are thought possibly to exert a membrane-stabilizing action, thus inhibiting radical-induced lipid peroxidation ${ }^{13}$. Carbon tetrachloride $\left(\mathrm{CCl}_{4}\right)$, a well-known potent hepatotoxic agent, is being used extensively to investigate hepatoprotective activity on various experimental animals ${ }^{14}$. Hepatic damage induced by $\mathrm{CCl}_{4}$ resulted in an increase in serum glutamic oxaloacetic transaminase (SGOT) and serum glutamic pyruvic transaminase (SGPT). The elevation of concentrations of these two serum enzymes is generally regarded as one of the sensitive markers of hepatic damage ${ }^{14}$.

The chemical composition of genus Polygonum especially its flavonoidal content as well as its reported pharmacological and antimicrobial activities provoked us to investigate the biological and antimicrobial activities of Polygonum bellardii All. together with its total flavonoid content spectrophotometrically. 


\section{MATERIAL AND METHODS}

\section{Plant material}

The aerial parts of Polygonum bellardii All. were collected during flowering stage in April 2007 from Assiut governorate and kindly identified and authenticated by Prof. Dr. Moamen. M. Zarea, Professor of Plant Taxonomy, Department of Botany, Faculty of Science, Assiut University, Assiut, Egypt. A voucher specimen was kept in the Department of Pharmacognosy, Faculty of Pharmacy, AlAzhar University, Assiut, Egypt, (Pb001).

\section{Instruments}

Ultrospec 1000, UV/visible Spectrometer, Pharmacia Biotech, Cambridge, England, Table-Top low speed Centrifuge L-500 (max speed $5000 \mathrm{r} / \mathrm{min}$.), Xiang Yi, Human Lab Instrument Co., Korea, and Digital Ultrasonic Cleaner , MTI Corporation, USA. Rotary microtome HM 355 S, Germany and Light Multihead Microscope, Miken Instrument, Ambala Cantt-133001, India.

\section{Chemicals}

Ascorbic acid and quercetin as an antioxidant standard (were obtained from Sigma-Aldrich Chemicals Co, Germany), Sylimarin as standard hepatoprotective drug (obtained from Pharco Pharmaceutical Co. Egypt) and 2,2-Diphenyl-1-picryl hydrazyl $(\mathrm{DPPH})$ (obtained from Sigma-Aldrich
Chemicals Co. Germany). Other chemicals used were of high analytical grade and obtained from Sigma-Aldrich and Merck companies.

\section{Extraction, fractionation and isolation of phenolic compounds}

The air-dried powdered flowering aerial parts $(2 \mathrm{Kg})$ of Polygonum bellardii All. were extracted by maceration and percolation with methanol till complete exhaustion (1:4 ratio) [four times each $8 \mathrm{~L}$, overnight]. The combined methanolic extracts were concentrated under reduced pressure till constant weight to give a syrupy residue $(150 \mathrm{~g})$. The extract was subjected to successive solvent fractionation on VLC with $n$-hexane, chloroform, ethyl acetate, $n$-butanol and methanol till complete exhaustion in each case to give $n$-hexane ( 20 g), chloroform (25 g), ethyl acetate (20 gm), $n$ butanol $(10 \mathrm{~g})$ and methanol $(50 \mathrm{~g})$. Using different chromatographic techniques (C.C., LH-20 and RP-18), compounds $\mathbf{1}$ and $\mathbf{2}$ were isolated from the chloroform fraction and identified as gallic $\operatorname{acid}^{15}$ and quercetin ${ }^{16}$, respectively, while compounds 3-6 were obtained from the ethyl acetate fraction and identified as quercetin-3- $O-(5$ "-acetyl- $\alpha$ arabinofuranoside $)^{16} \mathbf{3}$, quercetin-3- $O-\beta-\mathrm{D}$ glucopyranoside $^{16} \quad 4$, myricetin-3- $O$-(5"-acetyl$\alpha$-arabinofuranoside ${ }^{16} \mathbf{5}$, and myricetin-3-O- $\alpha$ arabinofuranoside $^{16} \mathbf{6}$. The structures of isolated (tested) compounds (1-6) are illustrated in (Fig. 1).<smiles>CCOc1cc(-c2oc3cc(O)cc(O)c3c(=O)c2OCCO)cc(O)c1O</smiles>

Compound

$\mathbf{R}_{1}$

$\mathrm{H}$

$\mathrm{H}$

$\mathrm{H}$

$\mathrm{OH}$

$\mathrm{OH}$
$\mathbf{R}_{\mathbf{2}}$

$\mathrm{H}$

acetyl arabinose

glucose

acetyl arabinose

arabinose

Fig. 1: Structures of tested compounds 1-6. 


\section{Animals}

Male albino rats (each 100-120 g), were bred and housed under standardized environmental conditions in the pre-clinical animal house, Pharmacology Department, Faculty of Medicine, Assiut University, Assiut, Egypt. The animals were fed with standard diet and free access to water. They were kept at 24$28^{\circ} \mathrm{C}$ temperature, $60-70 \%$ relative humidity, and $12 \mathrm{hrs}$ day and night cycle for one week to acclimatize to the environmental conditions.

\section{Test organisms}

Bacterial strains used in this study were: Escherichia coli, Pseudomonas aeruginosa as Gram-negative bacteria and Staphylococcus aureus, Bacillus subtilis as Gram-positive bacteria. Candida albicans was used for determination of antifungal activity. All strains were clinical isolates obtained from the Microbiological Laboratory, Microbiology Department, Faculty of Pharmacy, Al-Azhar University, Assiut, Egypt. All bacterial strains were cultivated in nutrient agar medium and incubated at $37^{\circ} \mathrm{C}$ for $24 \mathrm{hrs}$, while Candida albicans was cultivated in potato dextrose agar at $28^{\circ} \mathrm{C}$ for $48 \mathrm{hrs}$. Nystatin was used as reference antifungal (discs), and Cefotax as reference antibiotic (discs), (Oxoid Co. England).

\section{I- Evaluation of antioxidant activity ${ }^{17-20}$}

The antioxidant activity was determined firstly by TLC procedure $^{17}$ then by 2,2diphenyl-1-picrylhydrazyl (DPPH'), radical scavenging method ${ }^{17}$. The investigated extracts were dissolved in methanol $(1: 20, w / v)$ and applied $(10$ L) spotwise to TLC plate with silica gel as adsorbent. The plates were developed in an ethyl acetate - formic acid acetic acid - water (100:11:11:26, $v / v / v / v)$ as solvent system. The plates were sprayed with $0.2 \%(w / v) \mathrm{DPPH}^{\circ}$ in methanol reagent and observed in day light. $\mathrm{DPPH}^{\circ}$ radical scavenging activity was measured by spectrophotometric method ${ }^{18 \& 19}$. One milliliter of methanolic solution of compounds (1-6) isolated from the flowering aerial parts of Polygonum bellardii All. of various concentrations $(10-200 \mu \mathrm{g} / \mathrm{ml})$ was mixed with $1 \mathrm{ml}$ of methanolic solution of $\mathrm{DPPH}^{*}(200$ $\mu \mathrm{M})$. Similarly; $1 \mathrm{ml}$ methanolic solution of ascorbic acid and quercetin of various concentrations $(10-200 \mu \mathrm{g} / \mathrm{ml})$ were mixed with $1 \mathrm{ml}$ of DPPH solution. A mixture of $1 \mathrm{ml}$ of methanol and $1 \mathrm{ml}$ of methanolic solution of $\mathrm{DPPH}^{\circ}(200 \mu \mathrm{M})$ served as control. After mixing, all the solutions were incubated in dark for $30 \mathrm{~min}$ and then absorbance was measured at $517 \mathrm{~nm}^{20}$. The experiments were performed in triplicate using ascorbic acid and quercetin as a positive control standards and \% scavenging activity was calculated by using the following formula ${ }^{20}$.

$\%$ Scavenging $=\frac{\text { absorbance of control }- \text { absorbance of test }}{\text { absorbance of control }} \times 100$

Results of antioxidant activity of total methanolic extract and its fractions are recorded in (Table 1) and illustrated in (Fig. 2)

\section{II- Acute toxicity studies ${ }^{21}$}

The acute toxicity study for Polygonum bellardii All. was performed using albino rats $(120-150 \mathrm{~g})$ of either sex. The animals were fasted overnight prior to the experiment and maintained under standard conditions. The total methanolic extract of Polygonum bellardii All. was dissolved in $2 \%$ tween 80 and administered orally at doses increasing $(1,2,4$ and $8 \mathrm{~g} / \mathrm{kg} \mathrm{b.w.).} \mathrm{The} \mathrm{animals} \mathrm{were} \mathrm{remained}$ for $48 \mathrm{hr}$ under observation for any signs and symptoms of toxicity.

\section{III- Hepatoprotective activity ${ }^{22}$}

Previously prepared extracts (ethyl acetate, $n$-butanol and total alcohol) were separately taken in weighed amounts ( 2 and $4 \mathrm{~g}$ each) and solubelized in normal saline with the aid of $2 \%$ tween- 80 to obtain concentrations of 200 and $400 \mathrm{mg} / \mathrm{ml}$.

Experimental design: Rats were divided into 9 groups, each of 4 animals:

Group I Control (vehicle): Received $1 \%$ v/v Tween-80 in distilled water $(5 \mathrm{ml} / \mathrm{kg}$ body weight, p.o.) single daily dose for 7 consecutive days.

Group II $\left(\mathrm{CCl}_{4}\right.$ induced): Received $1 \% \mathrm{v} / \mathrm{v}$ Tween-80 in distilled water $(5 \mathrm{ml} / \mathrm{kg}$ body weight, p.o.) single daily dose for 7 consecutive days.

Group III (standard): Received standard drug Sylimarin $(100 \mathrm{mg} / \mathrm{kg}$ body weight 
p.o.) single daily dose for 7 consecutive days.

Group IV, V (test-1 and 2): Received total alcohol extract (200 and $400 \mathrm{~kg}$ body weight, p.o.) single daily dose for 7 consecutive days.

Group VI, VII (test-3 and 4): Received ethyl acetate extract (200 and $400 \mathrm{~kg}$ body weight, p.o.) single daily dose for 7 consecutive days.

Group VIII, IX (test-5 and 6): Received nbutanol extract (200 and $400 \mathrm{~kg}$ body weight, p.o.) single daily dose for 7 consecutive days.

Groups from II to IX have received $\mathrm{CCl}_{4}$ in olive oil ( $1: 1 \mathrm{v} / \mathrm{v}, 0.7 \mathrm{ml} / \mathrm{kg}$ body weight i.p.) single dose on the $4^{\text {th }}$ day only in addition to their basic treatments.

\section{Sample collection}

All rats were sacrificed by cervical decapitation separately after $24 \mathrm{hrs}$ of the last treatment. Blood samples of each group were collected into sterilized dry centrifuge tubes and rotated at $3000 \mathrm{r} / \mathrm{min}$. for 10 minutes to obtain clear serum. Liver was excised immediately for histopathological examination.

\section{Estimation of biochemical parameters}

The clear serum obtained after centrifugation was used for the estimation of serum glutamic oxaloacetic transaminase (SGOT), serum glutamic pyruvic transaminase (SGPT) and total bilirubin (TB). All the biochemical parameters were measured spectrophotometrically.

\section{Estimation of SGOT and SGPT}

It is based on the reaction of ketoglutrate with aspartate in case of AST (=SGOT) to form glutamate and oxaloacetate. In case of ALT (=SGPT) it is based on the reaction of ketoglutrate with alanine to form glutamate and pyruvate. The formed keton (pyruvate or oxaloacetate) reacts with 2,4-dinitro phenyl hydrazine hydrochloride in alkaline solution to give colored complex that determined spectrophotometrically at $505 \mathrm{~nm}^{23}$.

\section{Estimation of total bilirubin}

It is based on that, the serum bilirubin reacts with diazotized sulphanilic acid to give a purple azo-bilirubin dye, which measured colorimetrically at $540 \mathrm{~nm}^{24 \& 25}$. Results of effect of the total extract and fractions of Polygonum bellardii All. on SGOT, SGPT and total bilirubin of $\mathrm{CCl}_{4}$ treated Rats are recorded in (Table 2).

\section{Histopathological study ${ }^{22}$}

Liver is dissected out and the liver samples were excised from the experimental animals of each group and washed with normal saline. Initially the materials were fixed in $10 \%$ buffered neutral formalin. They were processed for paraffin embedding following the microtome technique. The sections were taken at 5 thickness processed in alcohol-xylene series and were stained with alum-haematoxylin and eosin. The sections were examined microscopically for the evaluation of histopathological changes of hepatic cells and results are illustrated in (Fig. 3).

\section{IV- Evaluation of antimicrobial activity}

\section{Preparation of the extracts for antimicrobial activity}

Concentrations of $5,10,25,50,75,100$, and $200 \mathrm{mg} / \mathrm{ml}$ of total methanolic extract and its fractions, $n$-hexane, chloroform, ethyl acetate and $n$-butanol were prepared separately in dimethyl sulphoxide (DMSO)

\section{Determination of antimicrobial activity ${ }^{26}$}

Agar cup diffusion method was used to detect inhibition zones caused by the total extract and fractions of the aerial parts of Polygonum bellardii. For determination of antibacterial activity bacterial cultures were adjusted to 0.5 McFarland turbidity standards and inoculated on $15 \mathrm{~cm}$ diameter nutrient agar plates. For the determination of antimycotic activity, the $C$. albicans was firstly adjusted to the concentration of $10^{6} \mathrm{cfu} / \mathrm{ml}$. By using a sterile cork porer and under aseptic conditions, cups were made in the medium in which fixed volumes from the different concentrations of the tested fractions were dispensed to fill the cups, using sterile micropipette. Plates were placed carefully in the incubators at $37^{\circ} \mathrm{C}$ for $24 \mathrm{hrs}$ for bacteria and at $28^{\circ} \mathrm{C}$ for $48 \mathrm{hrs}$ for fungi. After incubation the diameter of the clear zone of inhibition surrounding the samples was taken as a measure of the inhibitory power of the sample against the particular test organisms. Any zone of 
inhibition was recorded as positive results. Results of the antimicrobial activity of total extract and fractions of Polygonum bellardii All. on tested micro-organisms are recorded in (Table 3).

\section{Determination of $\mathrm{MIC}^{27}$}

The minimum inhibitory concentration (MIC) of the extracts was determined for each of the test organisms in triplicates. To $0.5 \mathrm{ml}$ of varying concentrations of the extracts $(0.5,1$, $2.5,5,10,25$, and $50 \mathrm{mg} / \mathrm{ml}), 2 \mathrm{ml}$ of nutrient broth was added and then a loopful of the test organism previously diluted to $0.5 \mathrm{McFarland}$ turbidity standard for (bacterial isolates) and $10^{6} \mathrm{cfu} / \mathrm{ml}$ (for fungal isolates) was introduced to the tubes. The procedure was repeated 6 times on the test organisms using the standard antibiotic (cefotax for bacteria and nystatin for fungal isolates). A tube containing nutrient broth only was seeded with the test organisms as described above to serve as control. Tubes containing bacterial cultures were then incubated at $37^{\circ} \mathrm{C}$ for $24 \mathrm{hrs}$, while tubes containing fungal spore cultures were incubated for $48 \mathrm{hrs}$ at room temperature $\left(28^{\circ} \mathrm{C}\right)$. After incubation the tubes were then examined for microbial growth by observing turbidity. Results of minimum inhibitory concentration (MIC) of the total extract and fractions of Polygonum bellardii All. are recorded in (Table 4).

\section{V- Estimation of total flavonoids content}

Aluminum chloride colorimetric method was used for total flavonoids determination ${ }^{28}$. The total extract of the plant material $(0.5 \mathrm{ml}$ of $1: 10 \mathrm{~g} / \mathrm{ml}$ ) in methanol was separately mixed with $1.5 \mathrm{ml}$ of methanol, $0.1 \mathrm{ml}$ of $10 \%$ aluminum chloride, $0.1 \mathrm{ml}$ of $1 \mathrm{M}$ potassium acetate and $2.8 \mathrm{ml}$ of distilled water. The mixture was kept at room temperature for 30 minutes. The absorbance of the reaction mixture was measured at $415 \mathrm{~nm}$. Calibration plot was generated by using quercetin solutions at concentrations from $12.5-100 \mathrm{~g} / \mathrm{ml}$ in methanol. Experiments were performed in triplicates and results are recorded as mean in figure 4 .

\section{Statistical analysis}

Data were analyzed by comparing values for different treatment groups with the values for individual controls. Results are expressed as mean \pm S.E ( $n=4$ animals). The significant differences among values were analyzed using analysis of variance (one-way Anova) followed by Dunnett's $t$ test for comparison between different groups. [ $\mathrm{p}<0.05$ was considered as significant, $p<0.01$ was considered as very significant].

\section{RESULTS AND DISCUSSION}

\section{I- Antioxidant activity}

$\mathrm{DPPH}^{\circ}$ is a relatively stable free radical which when encounters proton donors such as antioxidants, it gets quenched and the absorbance decreases ${ }^{29}$. In the present study, the direct measurement of radical scavenging activity was used for evaluation of antioxidant activity. Some isolated compounds from the flowering aerial parts of Polygonum bellardii exhibited good radical quenching activity against DPPH'. Results (Table 1 and Fig. 2) indicated good scavenging activity of the methanol extract and its fractions towards $\mathrm{DPPH}^{*}$ in comparison with ascorbic acid and quercetin. The ethyl acetate fraction showed maximum activity in comparison with total methanolic extract and other fractions, followed by $n$-butanol and chloroform fractions successively. The isolated compounds exhibited higher activity than total methanolic extract and fractions. Compounds $\mathbf{1}$ and $\mathbf{2}$ (gallic acid and quercetin) showed activity closely related to the references (ascorbic acid and quercetin), followed by compounds $6,4,5$ and $\mathbf{3}$. The obtained high antioxidant activity results of the isolated flavonoid compounds (Table 1, Fig. 2) are closely related to the chemical structure of their aglycone moieties and also the position of hydroxyl groups. The antioxidant activity of the aglycone (compound 2) is more potent than their corresponding glycosides (compounds $\mathbf{3}$ and $\mathbf{4}$ ) that are in good agreement with the published data ${ }^{30 \& 31}$. The presence of ortho-dihydroxylation of the B-ring of the flavonoid molecule, C2-C3 double bond and 4-oxo group of the ring $\mathrm{C}$ in addition to the presence of both 3-and 5hydroxyl moiety of the rings $\mathrm{C}$ and $\mathrm{A}$, play an important role in radical scavenging activity of the flavonoids ${ }^{16,30 \& 31}$. 
Table 1: Antioxidant activity of the total methanolic extract, fractions and isolated compounds (1-6) of Polygonum bellardii All.

\begin{tabular}{|c|c|c|c|c|c|c||}
\hline \multirow{2}{*}{$\begin{array}{c}\text { Extract/Fraction or } \\
\text { Compound }\end{array}$} & \multicolumn{5}{|c|}{ Concentration $(\mu \mathrm{g} / \mathrm{ml})$} \\
\cline { 2 - 7 } & \multicolumn{5}{|c|}{50} & \multicolumn{2}{|c||}{100} & 200 & - \\
\hline & \multicolumn{7}{|c|}{25} & \multicolumn{5}{|c||}{ inhibition } & $\mathrm{IC}_{50}$ \\
\hline Ascorbic acid & $47.1 \pm 2.03 \%$ & $66.3 \pm 1.79 \%$ & $86.9 \pm 3.12 \%$ & $98.8 \pm 1.54 \%$ & $99.6 \pm 3.10 \%$ & $14.5 \pm 2.92$ \\
\hline Quercetin & $45.0 \pm 2.95 \%$ & $65.0 \pm 2.88 \%$ & $85.0 \pm 3.62 \%$ & $97.3 \pm 0.91 \%$ & $99.1 \pm 3.22 \%$ & $15.1 \pm 2.25$ \\
\hline $\begin{array}{c}\text { Total methanolic } \\
\text { extract }\end{array}$ & $10.0 \pm 0.97 \%$ & $19.8 \pm 1.24 \%$ & $25.0 \pm 1.07 \%$ & $42.9 \pm 2.14 \%$ & $64.8 \pm 1.09 \%$ & $135.4 \pm 2.05$ \\
\hline$n$-Hexane Fr. & $05.8 \pm 0.45 \%$ & $13.8 \pm 1.21 \%$ & $20.8 \pm 1.13 \%$ & $35.9 \pm 3.14 \%$ & $41.9 \pm 1.45 \%$ & $253.4 \pm 1.91$ \\
\hline Chloroform Fr. & $15.8 \pm 3.20 \%$ & $21.8 \pm 1.65 \%$ & $36.8 \pm 1.88 \%$ & $50.9 \pm 2.98 \%$ & $67.9 \pm 0.78 \%$ & $98.1 \pm 3.02$ \\
\hline Ethyl acetate Fr. & $29.9 \pm 3.12 \%$ & $51.9 \pm 3.10 \%$ & $68.2 \pm 3.51 \%$ & $73.3 \pm 1.56 \%$ & $82.5 \pm 3.21 \%$ & $20.51 \pm 1.87$ \\
\hline$n$-Butanol Fr. & $26.8 \pm 2.66 \%$ & $44.9 \pm 2.88 \%$ & $60.1 \pm 2.43 \%$ & $71.1 \pm 3.32 \%$ & $77.3 \pm 1.88 \%$ & $34.7 \pm 2.32$ \\
\hline Compound 1 & $43.1 \pm 1.18 \%$ & $63.3 \pm 2.19 \%$ & $88.9 \pm 2.17 \%$ & $99.8 \pm 2.24 \%$ & $100 \pm 2.23 \%$ & $15.8 \pm 3.35$ \\
\hline Compound 2 & $42.0 \pm 1.35 \%$ & $61.0 \pm 2.11 \%$ & $83.0 \pm 2.12 \%$ & $94.3 \pm 1.41 \%$ & $97.1 \pm 2.52 \%$ & $18.5 \pm 4.30$ \\
\hline Compound 3 & $28.4 \% \pm 2.13$ & $43.5 \pm 0.09 \%$ & $68.6 \pm 1.62 \%$ & $76.3 \pm 0.98 \%$ & $85.6 \pm 2.04 \%$ & $23.4 \pm 2.31$ \\
\hline Compound 4 & $26.6 \pm 1.67 \%$ & $44.9 \pm 1.53 \%$ & $69.1 \pm 1.66 \%$ & $78.6 \pm 2.05 \%$ & $88.7 \pm 2.22 \%$ & $24.1 \pm 1.85$ \\
\hline Compound 5 & $27.7 \pm 1.32 \%$ & $46.6 \pm 1.52 \%$ & $72.8 \pm 1.43 \%$ & $77.6 \pm 3.00 \%$ & $86.3 \pm 1.76 \%$ & $22.4 \pm 4.11$ \\
\hline Compound 6 & $29.2 \pm 1.77 \%$ & $45.9 \pm 2.11 \%$ & $75.9 \pm 1.92 \%$ & $79.8 \pm 3.02 \%$ & $90.1 \pm 1.88 \%$ & $22.2 \pm 2.76$ \\
\hline
\end{tabular}

Notes: Compound 1: Gallic acid, 2: quercetin, 3: quercetin-3- $O$-(5"-acetyl- $\alpha$-arabinofuranoside), 4: quercetin-3- $O-\beta$-D-glucopyranoside, 5: myricetin-3- $O$ - $(5$ "-acetyl- $\alpha$-arabin-ofuranoside, and 6: myricetin-3- $O-\alpha$-arabinofuranoside.

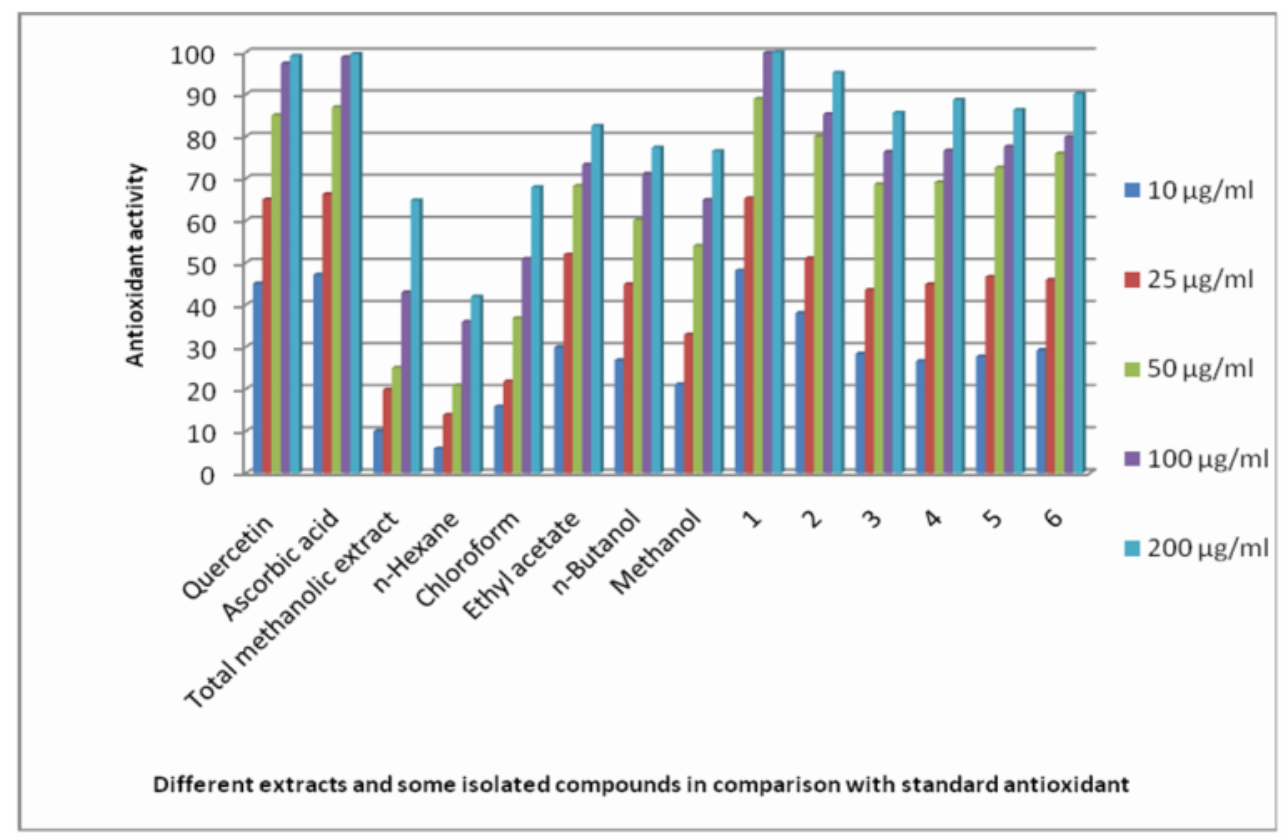

Fig. 2: Antioxidant activity of total methanolic extract, fractions and isolated compounds from Polygonum bellardii All.

Notes: 1: Gallic acid, 2: quercetin, 3: quercetin-3- $O-(5$ "-acetyl- $\alpha$-arabinofuranoside), 4: quercetin-3-O$\beta$-D-glucopyranoside, 5: myricetin-3- $O-(5 "$-acetyl- $\alpha$-arabinofuranoside, and 6: myricetin-3- $O$ $\alpha$-arabinofuranoside. 


\section{II- Acute toxicity studies}

The symptoms of toxicity were characterized by irritability, writhing, hypothermia, loss of motor coordination, sedation and deep sleep, followed by death. The total methanolic extract of Polygonum bellardii All. did not show signs of toxicity and mortality up to $4 \mathrm{~g} / \mathrm{kg}$ dose.

\section{III- Hepatoprotective activity}

$\mathrm{CCl}_{4}$ is one of the most commonly used hepatotoxin in the experimental study of liver disease ${ }^{32}$. The hepatotoxic effects of $\mathrm{CCl}_{4}$ are largely due to generation of free radicals ${ }^{33}$. $\mathrm{CCl}_{4}$ is biotransformed by the cytochrome P450 system to produce the trichloromethyl free radical $\left(\cdot \mathrm{CCl}_{3}\right)$ that reacts rapidly with oxygen to form a trichloromethyl-peroxy radical $\left(\cdot \mathrm{CCl}_{3} \mathrm{O}_{2}\right)$. This metabolite possibly attack membrane polyunsaturated fatty acids thereby causing lipid peroxidation leading to impairment of membrane function and liver injury $^{34}$. Damage of liver cell is reflected by an increase in the levels of hepatospecific enzymes; these are cytoplasmic and are released into circulation after cellular damage ${ }^{35}$. In this study significant increase in the SGOT and SGPT enzymes in the $\mathrm{CCl}_{4}$ treated group could be taken as an index of liver damage. Bilirubin is one of the most useful clinical clues to the severity of necrosis and its accumulation is a measure of binding, conjugation and excretory capacity of hypatocyte. The obtained results (Table 2) showed that; the total methanolic extract in addition to ethyl acetate and $n$-butanol fractions of Polygonum bellardii exhibited significant decrease in SGOT and SGPT enzymes and total bilirubin as compared with $\mathrm{CCl}_{4}$ treated group. Decrease in serum enzymes and bilirubin after treatment with the total extract and some fractions in liver damage induced by $\mathrm{CCl}_{4}$, indicated the effectiveness of the total extract and fractions in normal functional status of the liver. The $n$-butanol fraction (400 $\mathrm{mg} / \mathrm{kg}$ body weight) exhibited hepatoprotective activity nearly the same as sylimarin against carbon tetrachloride $\left(\mathrm{CCl}_{4}\right)$ induce hepatic injury in albino rats, while ethyl acetate fraction $(400 \mathrm{mg} / \mathrm{kg}$ body weight $)$ showed hepatoprotective activity higher than sylimarin. The obtained activity attributed to the presence of phytoconstituents like flavonoids and phenolic acids are known to possess hepatoprotective activity ${ }^{36}$.

Table 2: Effect of the total methanolic extract and fractions of Polygonum bellardii All. on SGOT, SGPT and total bilirubin of $\mathrm{CCl}_{4}$ treated rats.

\begin{tabular}{|c|c|c|c|c|}
\hline Animal group & $\begin{array}{c}\text { Concentration } \\
\mathrm{mg} / \mathrm{kg}\end{array}$ & SGOT (IU/L) & SGPT (IU/L) & $\begin{array}{c}\text { Total bilirubin } \\
\mathrm{Mg} / \mathrm{dL}\end{array}$ \\
\hline Control (vehicle) & - & $28.2 \pm 1.86$ & $23.6 \pm 1.17$ & $0.59 \pm 0.017$ \\
\hline $\mathrm{CCl}_{4}$ treated & 0.7 & $114.0 \pm 9.82^{\# \#}$ & $94.8 \pm 5.79^{\#}$ & $1.31 \pm 0.083^{\#}$ \\
\hline Sylimarin & 100 & $42.2 \pm 2.83^{* *}$ & $35.2 \pm 2.58^{* *}$ & $0.62 \pm 0.020^{* *}$ \\
\hline $\begin{array}{c}\text { Total methanolic } \\
\text { extract }\end{array}$ & 200 & $68,4 \pm 3.91^{*}$ & $58.6 \pm 2.39^{*}$ & $0.80 \pm 0.024 *$ \\
\cline { 2 - 5 } & 400 & $49.3 \pm 2.87^{* *}$ & $39.8 \pm 2.13^{*}$ & $0.71 \pm 0.017^{*}$ \\
\hline \multirow{2}{*}{\begin{tabular}{c} 
Ethyl acetate Fr. \\
\cline { 2 - 5 }
\end{tabular}} & 200 & $56.6 \pm 2.68^{*}$ & $42.1 \pm 1.89 *$ & $0.76 \pm 0.028^{*}$ \\
\hline \multirow{2}{*}{$n$-Butanol Fr. } & 200 & $34.4 \pm 1.93^{* *}$ & $28.9 \pm 1.87 * *$ & $0.54 \pm 0.027 * *$ \\
\cline { 2 - 5 } & 400 & $41.8 \pm 1.96^{* *}$ & $33.7 \pm 1.88^{* *}$ & $0.62 \pm 0.020^{* *}$ \\
\hline
\end{tabular}

Notes: Values are mean $\pm \mathrm{SEM}$; number of rats used in each group $=4 ;{ }^{\#} \mathrm{p}<0.05$, ${ }^{\#} \mathrm{p}<0.01$ Compared with the control group, ${ }^{*} \mathrm{p}<0.05, * * \mathrm{p}<0.01$ Compared with the $\mathrm{CCl}_{4}$ group. 
Histological Changes: Histology of liver section of control group showing normal histological architecture (Fig 3-A), whereas that of $\mathrm{CCl}_{4}$ treated rat liver sections showed cloudy swelling and degeneration of hepatocytes. Necrosis of cells was also observed with broken cell pieces, irregular appearance due to oozing of cell materials and cell death (Fig 3-B). The histogram of groups administered $\mathrm{CCl}_{4}$ and Polygonum bellardii (total extract at $200 \mathrm{mg} / \mathrm{kg}$ and $n$-butanol fraction at $200 \mathrm{mg} / \mathrm{kg}$ ) showed normal and affected areas of liver patches adjacent to each other. The degenerative changes, necrosis and haemorrhage were less observed (Fig 3-D and 3-E). Furthermore, the degenerative changes and necrosis were obscured in the standard (sylimarin) group; in addition to groups administered other fractions of Polygonum bellardii (ethyl acetate at 200 and $400 \mathrm{mg} / \mathrm{kg}$ and $n$-butanol at $400 \mathrm{mg} / \mathrm{kg}$ ) ( Fig. 3F-H) thus confirming the hepatoprotective effect of Polygonum bellardii. The remarkable hepatoprotective effect in $\mathrm{CCl}_{4}$-induced liver damage could be due to the phenolic constituents as flavonoids present in the plant ${ }^{37}$

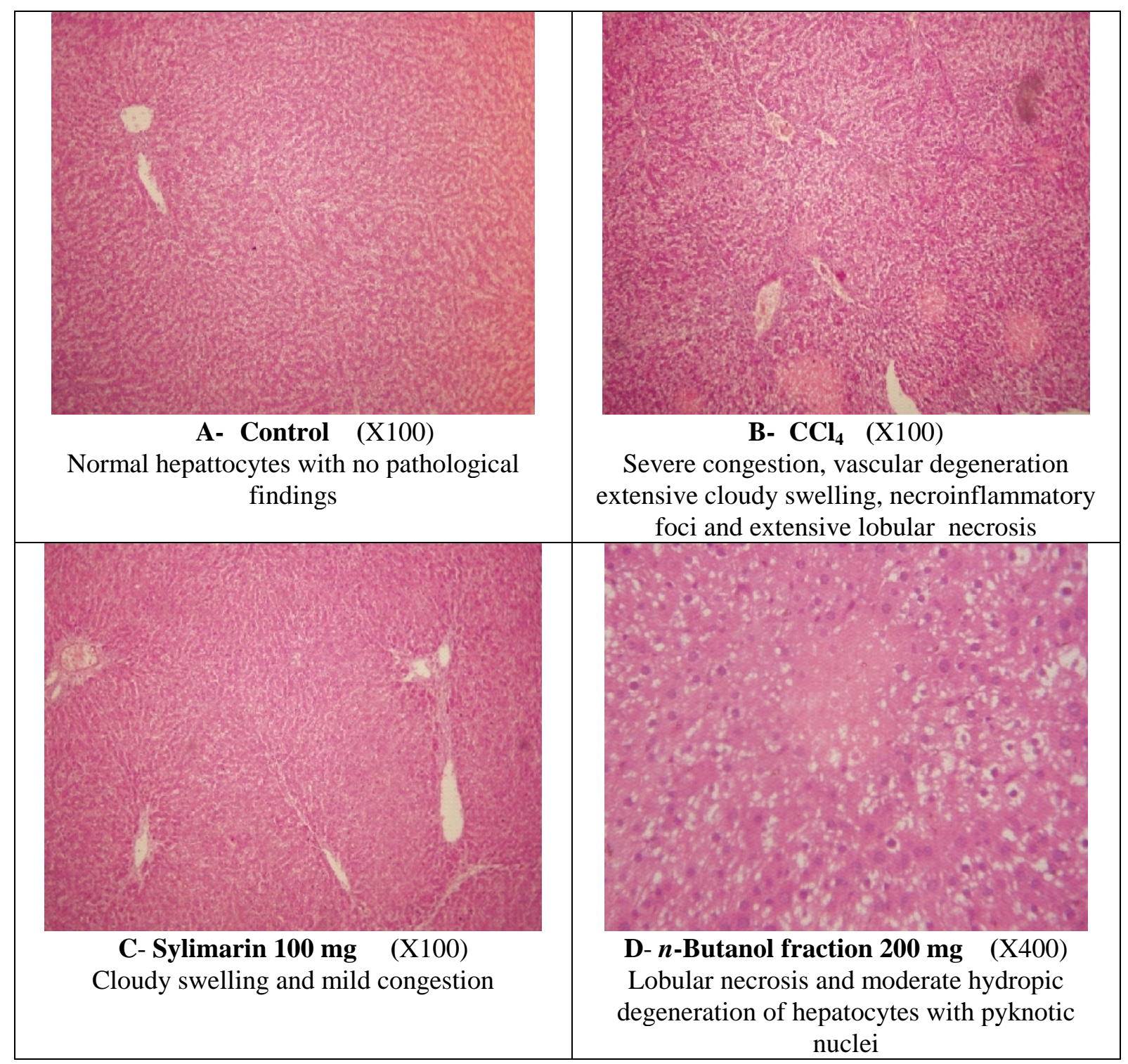




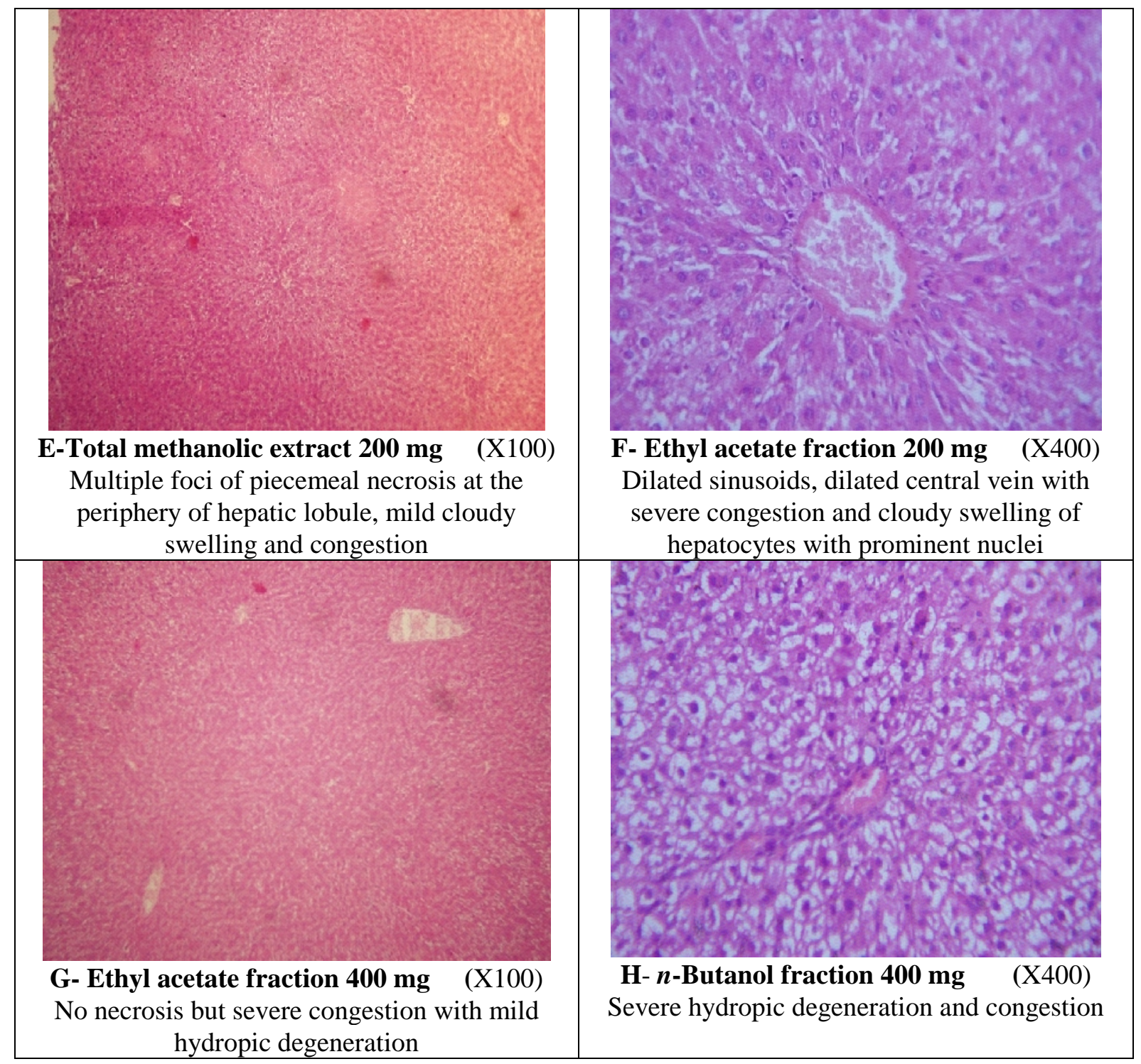

Fig. 3: Histopathological findings in rat liver sections after administration of total methanolic extract and fractions of Polygonum bellardii in comparison with hepatoprotective reference substance (sylimarin) and hepatotoxic agent $\mathrm{CCl}_{4}$ (Hematoxylin-eosin staining).

\section{IV- Antimicrobial activity}

The results (Tables 3 and 4) showed remarkable antibacterial activity of the different extracts under investigation against Gram positive and Gram negative bacteria especially with ethyl acetate and $n$-butanol fractions which showed good antibacterial activity. Also the different extracts exhibited antifungal activity compared with Nystatin (antifungal drug). The maximum antifungal activity was obtained with ethyl acetate and $n$ butanol fractions. This antimicrobial activity may be due to the presence of phenolic constituents as flavonoids, lignans, and phenolic acids in different extracts of the flowering aerial parts of the plant.

\section{V- Total flavonoids}

Polyphenolic compounds have an important role in stabilizing lipid oxidation and are associated with antioxidant activity. Results (Fig. 4) indicated that, the total flavonoids of the methanolic extract obtained from the flowering aerial parts of Polygonum bellardii All. were $185.2 \pm 1.03 \mathrm{mg} / \mathrm{g}$ dried extract. The obtained results confirmed the above results of antioxidant and hepatoprotective activity of the plant. 
Table 3: Results of the antimicrobial activity of total methanolic extract and fractions of Polygonum bellardii All. on tested micro-organisms.

\begin{tabular}{|c|c|c|c|c|c|c|}
\hline \multirow[b]{2}{*}{ Sample } & \multirow[b]{2}{*}{$\begin{array}{l}\text { Conc. } \\
\text { (mg/ml) }\end{array}$} & \multicolumn{5}{|c|}{ Inhibition zone diameter ( $\mathrm{mm} /$ sample) } \\
\hline & & $\begin{array}{c}\text { Staphylococcus } \\
\text { aureus }\end{array}$ & $\begin{array}{l}\text { Bacillus } \\
\text { subtilis }\end{array}$ & $\begin{array}{c}\text { Escherichia } \\
\text { coli }\end{array}$ & $\begin{array}{c}\text { Pseudomonas } \\
\text { aeurginosa }\end{array}$ & $\begin{array}{l}\text { Candida } \\
\text { albicans }\end{array}$ \\
\hline \multirow{3}{*}{$\begin{array}{c}\text { Total } \\
\text { methanolic } \\
\text { extract }\end{array}$} & 100 & 20 & 25 & 20 & 20 & 20 \\
\hline & 50 & 18 & 23 & 17 & 19 & 15 \\
\hline & 25 & 15 & 19 & 15 & 13 & 13 \\
\hline \multirow{3}{*}{$\begin{array}{l}n \text {-Hexane } \\
\text { Fr. }\end{array}$} & 100 & 17 & 17 & 18 & 15 & 15 \\
\hline & 50 & 13 & 14 & 15 & 13 & 13 \\
\hline & 25 & 11 & 13 & 13 & 11 & 11 \\
\hline \multirow{3}{*}{$\begin{array}{c}\text { Chloroform } \\
\text { Fr. }\end{array}$} & 100 & 19 & 15 & 18 & 17 & 17 \\
\hline & 50 & 16 & 13 & 17 & 15 & 15 \\
\hline & 25 & 13 & 13 & 14 & 11 & 13 \\
\hline \multirow{3}{*}{$\begin{array}{c}\text { Ethyl } \\
\text { acetate Fr. }\end{array}$} & 100 & 24 & 25 & 23 & 25 & 30 \\
\hline & 50 & 21 & 23 & 18 & 23 & 27 \\
\hline & 25 & 17 & 15 & 15 & 18 & 22 \\
\hline \multirow{3}{*}{$\begin{array}{c}n \text {-Butanol } \\
\text { Fr. }\end{array}$} & 100 & 22 & 23 & 21 & 20 & 15 \\
\hline & 50 & 20 & 18 & 19 & 18 & 12 \\
\hline & 25 & 17 & 15 & 15 & 14 & 11 \\
\hline
\end{tabular}

Table 4: Minimum inhibitory concentration (MIC) of the total methanolic extract and fractions of Polygonum bellardii All.

\begin{tabular}{|c|c|c|c|c|c|c|c|}
\hline \multirow{2}{*}{ Organism } & \multicolumn{5}{|c|}{ MIC (mg/ml) } & \multirow{2}{*}{$\begin{array}{c}\begin{array}{c}\text { MIC } \\
(\mu \mathrm{g} / \text { disc })\end{array} \\
\text { Cefotax }\end{array}$} & \multirow{2}{*}{$\begin{array}{c}\begin{array}{c}\text { MIC } \\
(\mu \mathrm{g} / \mathrm{disc})\end{array} \\
\text { Nystatin }\end{array}$} \\
\hline & Tot. & Hex & Ch. & Eth. & But. & & \\
\hline \multirow{5}{*}{$\begin{array}{l}\text { Staphylococcus aureus } \\
\text { Bacillus subtilis } \\
\text { Escherichia coli } \\
\text { Pseudomonas aeurginosa } \\
\text { Candida albicans }\end{array}$} & 5.0 & 25 & 10 & 2.5 & 2.5 & 30 & - \\
\hline & 2.5 & 10 & 10 & 5.0 & 5.0 & 15 & - \\
\hline & 5.0 & 10 & 5.0 & 5.0 & 5.0 & 30 & - \\
\hline & 10 & 25 & 25 & 2.5 & 5.0 & 30 & - \\
\hline & 10 & 25 & 10 & 1.0 & 25 & - & 25 \\
\hline
\end{tabular}

Notes: Tot: total methanolic extract, Hex: $n$-hexane fraction, Ch: chloroform fraction, Eth: ethyl acetate fraction, and But: $n$-butanol fraction.

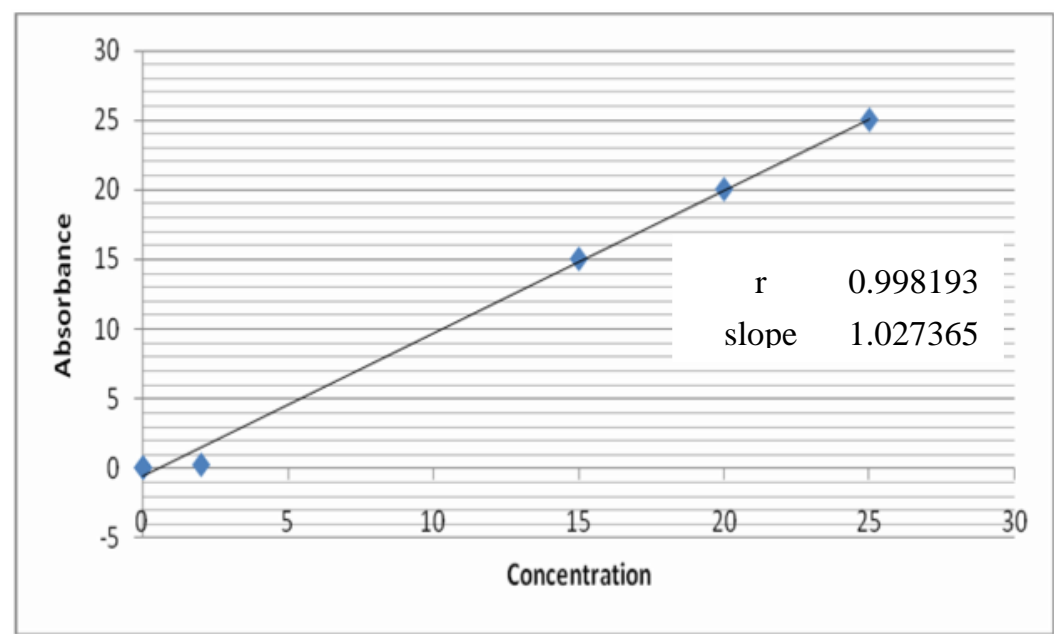

Fig. 4: Calibration curve of quercetin in $\mathrm{MeOH}$ at $415 \mathrm{~nm}$. 


\section{Acknowledgment}

Authors are grateful for Dr. Nesreen Abd Al-Tawab, Associate Prof of Pathology, Department of Pathology, Faculty of Medicine, Minia University, Minia-Egypt for her support in histopathological study.

\section{REFERENCES}

1. L. Boulos and M. N. El-Hadidi, "The Weed Flora of Egypt", The American University, Cairo Press, 1984, pp. 21-34.

2. L. Hsin-Tang, N. Sui-Lin, H. Ya-Yin and W. She-Ching, "Potential antioxidant components and characteristics of fresh Polygonum multiflorum", Journal of Food and Drug Analysis, 18, 120-127 (2010).

3. D. Mittal, "Hepatoprotective effects of Polygonum bistorta and active principles on albino rats intoxicated with carbon tetrachloride and paracetamol", Toxicology Letters, 1895, 557-561(2009).

4. Y. Pan, X. Zhang, H. Wang, Y. Liang, J. Zhu, H. Li, Z. Zhang and Q. Wu, "Antioxidant potential of ethanolic extract of Polygonum cuspidatum and application in peanut oil", Food Chemistry, 105, 15181524 (2007).

5. S. N. López, M. G. Sierra, S. J. Gattuso, R. L. Furlàn and S. A. Zacchino, "An unusual homoisoflavanone and a structurally-related dihydrochalcone from Polygonum ferrugineum (Polygonaceae)", Phytochemistry, 67, 2152-2158 (2006).

6. F. Zhang, W. Chen and L. Sun, "LCVWD-MS-Determination of three anthraquinones and one stilbene in the quality control of crude and prepared roots of Polygonum multiflorum Thunb", Chromatographia, 67, 869-874 (2008).

7. B. K. Datta, M. M. Rahman, A. I. Gray, A. H. Sayed, A. A. Auzi and S. D. Sarke, "Polygosumic acid, a new cadinane sesquiterpene from Polygonum viscosum, inhibits the growth of drug-resistant Escherichia coli and Staphylococcus aureus (MRSA) in-vitro", Journal of Natural Medicines, 61, 391-396 (2007).

8. K. Xiao, L. Xuan, Y. Xu, D. Bai and D. Zhong, "Constituents from Polygonum cuspidatum", Chemical Pharmaceutical Bulletin, 50, 605-608 (2002).

9. X. Li, M. Yu, D. Meng, Z. Li and L. Zhang, "A new chromone glycoside from
Polygonum capitatum", Fitoterapia, 78, 506-509 (2007).

10. Z. Jiang, J. Xu, M. Long, Z. Tu, G. Yang and G. He, "2,3,5,4'-tetrahydroxystilbene-2- $O$ - $\beta$-D-glucoside (THSG) induces melanogenesis in B16 cells by MAP kinase activation and tyrosinase upregulation", Life Sciences, 85, 345-350 (2009).

11. K. E. Heim, A. R. Tagliaferro and D. J. Bobilya, "Flavonoid antioxidants, chemistry, metabolism and structureactivity relationships", Journal of Nutritional Biochemistry, 13, 572-584 (2002).

12. L. C. Wilms, J. C. Kleinjans, E. J. Moonen and J. J. Briedé, "Discriminative protection against hydroxyl and superoxide anion radicals by quercetin in human leucocytes in-vitro", Toxicology, 22, 301-307 (2007).

13. J. Kinjo, M. Hitoshi and R. Tsuchihashi, "Hepatoprotective constituents in plants: protective effects of natural occurring flavonoids and miscellaneous phenolic compounds as determined in a HepG2 cell cytotoxicity assay", Journal of Natural Medicines, 60, 36-41 (2006).

14. M. N. Berry, H. J. Halls and M. B. Grivell, "Techniques for the pharmacological and toxicological studies with isolated hepatocyte suspension", Life Sciences, 51, 213-218 (1992).

15. L-N. Wang, B-X. Xu, P-X. Cao and G-Y. Liang, "Studies on the Chemical Constituents of Polygonum runcinatum Buch-Ham. var. sinense Hemsl", Natural Product Research, 21, 73-75 (2009).

16. Ø. M. Andersen and K. R. Markham, "Flavonoids, Chemistry, Biochemistry and Applications", CRC Press Taylor \& Francis Group 6000 Broken Sound Parkway NW, Suite 300 Boca Raton, London, New York, 2006, pp. 52-82.

17. M. Zoran, K. Nada, L. Branislava and C. Tatjana, "Antioxidant Activity of Yellow Dock (Rumex crispus L., Polygonaceae) Fruit Extract", Phytotherapy Research, 25, 102-105 (2011).

18. M. S. Blois, "Antioxidant Determination by the Use of a Stable Free Radical", Nature, 181, 1199-1200 (1958).

19. M. N. Qureshi, B. S. Kuchekar, N. A. Logade and M. A. Haleem, "in-vitro Antioxidant and in-vivo Hepatoprotective 
activity of Leucas ciliata leaves", Records of Natural Products, 4, 124-130 (2010).

20. A. A. Olajire and L. Azeez, "Total antioxidant activity, phenolic, flavonoid and ascorbic acid contents of Nigerian vegetables", African Journal of Food Science and Technology, 2, 22-29 (2011).

21. P. Suman, S. N. Siva, P. P. Durga, C. D. Subas, S. Vikas and J. Amol, "Hepatoprotective Activity of Crude Flavonoids Extract of Cajanus scarabaeoides (L) in Paracetamol Intoxicated Albino Rats", Asian Journal of Pharmaceutical and Biological Research, 1, 22-27 (2011).

22. K. R. Subash, K. S. Ramesh, B. V. Charian, F. Britto, N. J. Rao and S. Vijaykumar, "Study of Hepatoprotective Activity of Solanum nigrum and Cichorium intybus", International Journal of Pharmacology, 7, 504-509 (2011).

23. S. Reitman and S. A. Frankel, "Colorimetric method for the determination of serum glutamic oxalacetic and glutamic pyruvic transaminase", American Journal of Clinical Pathology, 28, 56-63 (1957).

24. W. G. Dangerfield and R. Finlayson, "Estimation of bilirubin in serum", Journal of Clinical Pathology, 6, 173-177 (1957).

25. M. T. Malloy and K. A. Evelyn, "The determination of bilirubin with the photoelectric colorimeter", Journal of Biological Chemistry, 112, 481-491 (1937).

26. National Committee for Clinical Lab. Standards, Performance Standards of Antimicrobial Disk Susceptibility Test $\mathbf{M}_{2-}$ $\mathrm{T}_{4}$, Villanva, Po, USA (1994).

27. M. H. S. Hediat and M. Najat, "Antimicrobial activity and phytochemical analysis of Polygonum aviculare L. (Polygonaceae), naturally growing in Egypt", Australian Journal of Basic and Applied Sciences, 3, 2008-2015 (2009).

28. C. Chang, M. Yang, H. Wen and J. Chern, "Estimation of total flavonoid content in propolis by two complementary colorimetric methods", Journal of Food and Drug Analysis, 10, 178-182 (2002).

29. C. D. Sadik, H. Sies and T. Schewe, "Inhibition of 15-lipoxygenases by flavonoids: structure-activity relations and mode of action", Biochemical Pharmacology, 65, 773-78 (2003).
30. G. S. Sim, B. C. Lee and H. S. Cho, "Structure activity relationship of antioxidative property of flavonoids and inhibitory effect on matrix metalloproteinase activity in UVairradiated human dermal fibroblast", Archives of Pharmacal Research, 30, 290298 (2007).

31. K. E. Heim, A. R. Tagliaferro and D. J. Bobilya, "Flavonoid antioxidants: chemistry, metabolism and structureactivity relationships", Journal of Nutritional Biochemistry, 13, 572-584 ((2002).

32. G. Cao, E. Sofic and R. L. Prior, "Antioxidant and prooxidant behavior of flavonoids: Structure-activity relationships", Free Radical Biology \& Medicine, 22, 749-760 (1997).

33. J. Xiao-feng, Q. Jie and L. Yan-hua, "The role of hepatoprotective effect of a flavonoid-rich extract of Salvia plebeia R.Br. on carbon tetrachloride induced acute hepatic injury in mice", Journal of Medicinal Plants Research, 5, 1558-1563 (2011).

34. R. O. Recknagel, E. A. Glende, J. J. A. Dolak and R. C. L. Waller, "Mechanism of carbon tetrachloride toxicity", Pharmacology and Therapeutics, 43, 139154 (1989).

35. N. J. Merlin and V. Parthasarathy, "Antioxidant and hepatoprotective activity of chloroform and ethanol extracts of Gmelina asiatica aerial parts", Journal of Medicinal Plants Research, 5, 533-538 (2011).

36. N. L. Baek, Y. S. Kim, J. S. Kyung and K. H. Park, "Isolation of anti-hepatotoxic agent from the roots of Astragalus membranaceous", Korean Journal of Pharmacology, 27, 111-116 (1996).

37. M. k. Sang, K. Kyungsu, H. J. Eun, J. YuJin, W. N. Chu, U. Byung-Hun and P. Cheol-Ho, "Hepatoprotective Effect of Flavonoid Glycosides from Lespedeza cuneata against Oxidative Stress Induced by tert-Butyl Hyperoxide", Phytotherapy Research, 25, 1011-1017 (2011). 